\title{
JUDÍOS EN LA ESPAÑA DE LOS AUSTRIAS
}

El título de esta modesta contribución quizás sorprenda. De sobra es sabido que después del decreto de 1492 no podían vivir judíos en España so pena de muerte. La Inquisición descubrió judaizantes, criptojudíos; que llegaran a España judíos que no negaban su condición de tales sólo pudo ocurrir en circunstancias muy excepcionales. Sin embargo, se dieron casos; algunos hemos descubierto a través de la correspondencia del tribunal de la Inquisición de Sevilla con el de la Suprema, y, sin duda, un estudio más completo de la documentación permitirá descubrir otros. Vamos a reseñar con toda brevedad estos casos ${ }^{1}$.

El 5 de agosto de 1597 escribía la Inquisición de Sevilla a la Suprema: "Aurá más de un año que vino a esta ciudad un Jacobo Crudo, judío de nación, el qual pasó a esa Corte con licencia del marqués de Villarreal, capitán general de Ceuta, y con cartas del duque de Medina ${ }^{2}$ a lo que dezía, y buelto a esta ciudad anda en hábito de cristiano, y trata y contrata en ella con mucha publicidad, de lo que a dado mucho escándalo, y porque el conocimien. to desto incumbía a la justicia seglar no se ha trat ado dello en este Sancto Officio hasta que estos días emos recibido las cartas del obispo de Ceuta que van con ésta (no se hallan en este expediente), y aviéndole llamado mostró una licencia del Adelantado de Castilla por tiempo de quatro meses que se cumplieron por mayo de 96 . Y por el mucho perjuicio que se entiende haría su estada en esta ciudad y el deservicio que della resulta a Nuestro Señor y a S.M. nos pareció mandarle que se bolviese christiano;

${ }^{1}$ La documentación consultada pertenece a la sección de Inquisición del Archivo Histórico Nacional de Madrid, a la que se refieren las signaturas de los legajos que serán citados. Todos ellos pertenecen a la correspondencia de Sevilla con el Consejo de la Suprema Inquisición. El espacio explorado abarca los años 1590-1700, con algunas lagunas.

${ }^{2}$ El duque de Medinasidonia era Capitán General de las costas de Andalucía (o sea, el reino de Sevilla). 
pues dezía vino con este intento y que lo quería ser; donde no, se pusiese en habito de judío y saliese destos Reinos, y ni uno ni otro a hecho, de que a parecido dar noticia a V.S."

La respuesta de Madrid puede colegirse de esta otra carta que le enviaron los inquisidores sevillanos: "Luego que recibimos la de V.A. del 19 del pasado ordenamos que un notario del Secreto supiese del Asistente ${ }^{3}$ desta ciudad si procedía contra Jacobo Crudo, el qual respondió que aunque le conocía no procedía contra él, y ansí hecimos las demás diligencias que V.S. mandó, y exhibió las licencias con que dice aver residido en (estos reinos), cuyos traslados con su confesión embiamos con esta; y por ser cumplidos los términos dellas lo hicimos retener preso en la cárcel real hasta que V.S. otra cosa mande, y de los muchos tratos y comercios que tiene con mercaderías y rescates de cautivos ${ }^{4}$ entendemos que su asistencia en estos Reinos es por sus intereses, paliados so color de decir que se a de bolver christiano".

Más de dos meses después, el 6 de diciembre del citado año, la Inquisición de Sevilla recordaba a sus superiores el asunto de Crudo, y que lo habían puesto preso por no haberlo querido hacer el Ásistente. Había llegado a Sevilla un compañero suyo, Abraham Villalón, en hábito de cristiano, que hacía 14 años residía en Lisboa "con ciertas licencias que dize son de S.M. y del marqués de Villarreal; le tomamos declaración y la remitimos a V.S. con dichas licencias y lo embiamos a la cárcel en compañía de Jacobo Crudo, y suplicamos nos mande lo que se ha de hacer en ambas causas" 5 .

En el fondo que hemos explorado no hemos hallado más noticias de este Jacobo Crudo, pero si de un David Crudo, tal vez hijo suyo. En diciembre de 1640 se había producido el levantamiento de Portugal, pero Ceuta, por excepción entre las posesiones lusitanas, se mantuvo unida al reino de Castilla. Tal vez se refiera a este asunto la petición, cursada por el cribunal de Sevilla el 8 de enero de 1641, del alférez Bartolomé Collado, vecino de Ceuta, en nombre de David Crudo, "judío de nación, vecino de Tetuán y estante en dicha ciudad de Ceuta que pide licencia para venir a España a dar dos avisos al duque de Medinasidonia que importan al servicio de S.M. y que no son cosas para por escrito". De Madrid

${ }^{3}$ Era el título que se daba al corregidor o representante del poder real en Sevilla.

${ }^{4}$ Es decir, que se trataba de un mercader de esclavos negros.

${ }^{5}$ Inquisición, 2.952, caja $I^{a}$. Los expedientes de estos legajos no están numerados, y con frecuencia tampoco están colocados por orden cronológico. 
respondieron que se le diera permiso para ir a ver al duque "y no pase de allí, sino que se vuelva luego"'.

De un género muy distinto es el suceso del que informaba el tribunal de Sevilla en carta de 3 de abril de 1628: "Haviendo aportado a Gibraltar abrá ocho meses un navío con algunos moros y treinta judíos, se vendieron estos por orden de S.M. en pública almoneda, rematándose en un vecino de aquella ciudad en 40.000 reales aplicados para las fortificaciones de aquel puerto, y aviéndolos el comprador remitido a Ceuta a buelto a traer a Gibraltar diez judíos de los que compró para servirse dellos, y así lo tiene pedido al Tribunal por haverlos detenido en la cárcel real el Comisario ${ }^{7}$, y por ser cosa nueva haver esclavos judíos, y muy peligroso que estén en España entremetidos con cristianos y comunicando con ellos, nos ha parecido comunicarlo a V.A." La respuesta fue que el dueño debía sacarlos de España cuanto antes ${ }^{8}$.

Casi un año después, en 6 de marzo de 1629, Sevilla ampliaba la comunicación anterior con un detalle que me parece de bastante interés como para que algún erudito bibliófilo le siga la pista: "Los días pasados dió al través en Gibraltar un navio de moros y judíos que allí fueron presos, y en él se halló un becerro ${ }^{9}$ en que están escritos los libros del Pentateuco que los judíos suelen leer los sábados en sus sinagogas y algunos libros en lengua hebrea, todo lo qual se trujo a esta Inquisición". Allí fueron examinados por un monje jerónimo del convento de Ntra. Sra. de Gracia de Carmona, hombre versado en hebreo, el cual declaró que "seis de los libros eran litúrgicos, libros de oraciones, impresos en Venecia para la iglesia y congregación de España, y de ellos a avido dos impresiones, lo que nos da a entender que aviéndose gastado y repartido la primera se hizo la segunda, que es señal que en España deve haver muchas congregaciones de judíos ocultas que se corresponden con los de Venecia. Ha decidido que dicho monje lea todos los libros por si pudiera descubrirse algún indicio". Respuesta de la Suprema: "Como parece"10.

Siguen muchos años sin noticias de este género hasta que el 19 de junio de 1663 Sevilla escribe haber tenido noticia por los comisarios inquisitoriales residentes en Cádiz, el Puerto de Santa María y Tarifa de haber desembarcado en dichos puertos algu-

\footnotetext{
${ }^{6}$ Inquisición, 2.976.

${ }^{7}$ Delegado de la Inquisición en toda población de alguna importancia.

${ }^{8}$ Inquisición, 2.965.

${ }^{8}$ Un libro escrito en pergamino.

${ }^{10}$ Inquisición, 2.966.
} 
nos judíos de nación ${ }^{11}$ con el pretexto de querer convertirse al cristianismo, "y otros que sin este pretexto, sino el de comerciar, se pasan a ellos, unos y otros sin licencia del limo. Sr. Inquisidor General y de V. A. ${ }^{12}$, por lo qual parece preciso poner algún remedio por el escándalo que puede seguirse, y aunque conocemos a los judíos a quienes consienten las justicias por causa de los comercios y en virtud de papeles que traían para su asistencia, tiene que reparar el modo de proceder contra ellos, por quanto se presume tendrán orden de S.M. las justicias para tolerarlos, nos parece debían tener licencia de V. A. y convenía supiesen era esta diligencia precisa, porque sin ella puede introducirse desorden en que pasen muchos judíos a estos reinos y con el trato y comunicación inficionen alguna gente, lo cual también se puede temer en aquellos que dicen se vienen a ser cristianos, lo qual solo se puede hacer constar por su aserción, pues si en sus tierras lo dixeran no sólo les negaran el pasaporte sino que se expusieran a ser castigados, consideración que les favorece y empeña a que por el medio más suave se procure no queden esclavos, como pretende el gobernador de Tarifa lo son Juda y Mengen Abram que pasaron a aquel puerto sin pasaporte, por lo qual, según el concierto que se dice tener hecho el gobernador de Ceuta con los lugares confinantes de Berbería quedan captivos los moros o judíos que sin carta se pasan a estos Reinos, y con este animo de que se vuelvan [¿cristianos?] entregó el gobernador de Ceuta dichos dos judíos, los quales vinieron a esta Inquisición, y los remitimos al ordinario para que fuesen instruidos y baptizados, y como así en estos como en los que pasan sin dicho pretexto se nos ofrecen inconvenientes en que queden en estos Reinos, por el daño que puede temerse pasando muchas familias, suplicamos a V.A. nos ordene lo que deve hacerse con los que dicen quieren ser christianos y si se les deve ayudar a que no queden esclavos, y [qué se debe hacer] con los que vienen a comerciar sin licencia..."

La Suprema dilató la respuesta, hasta que en septiembre, a nueva instancia de los inquisidores de Sevilla, decretó: "Escrívase a los inquisidores que prendan a los judíos de profesión que entrasen en estos reinos sin licencia de Su S: llma. [el Inquisidor General] y los pongan presos en las cárceles reales de donde se hallasen, procurando escusar su comunicación, y den cuenta al

11 "Judíos de nación o de la nación" era el nombre que solía darse a los marranos o criptojudíos portugueses, pero se trata de judíos de otras procedencias, pues al decir que querían volverse cristianos se supone que no estaban bautizados.

${ }^{12} \mathrm{El}$ conseịo de la Suprema Inquisición tenía tratamiento de Alteza. 
Consejo de las personas que fueren e informen de las que han venido y están de presente en el Distrito de Sevilla, como se llaman, si han traído algunas mercaderías y a que fin han venido"13.

El tribunal de Sevilla contestó en 27 de noviembre que los citados judíos quedaban presos en Cádiz y se enviaban los autos. "Por ellos y papeles que traían no resulta cosa en contrario de lo que declararon: que se pasavan a estos reinos a ser cristianos, y porque el alcaide de la cárcel real de Cádiz ha imbiado el memorial que está en los autos pidiendo se le excuse la costa que estos judíos hacen, suplicamos a V.A. mande lo que debemos executar en este y otros casos semejantes". La respuesta de la Suprema fue: "Que por lo que toca a la Inquisición se alce la mano por ahora y los vea un calificador que les advierta lo que han de hacer, y entréguese al ordinario eclesiástico ${ }^{14}$ y el comisario tenga cuidado de como proceden, y que si quisieren ir a otro lugar digan adónde, y por cuánto tiempo y la causa"15.

En 1671 la Inquisición de Sevilla cursaba a Madrid los autos instruidos con motivo de la entrada en España sin licencia de Jacobo Mexía, "judío de nación”, el cual mostraba un pasaporte expedido por el duque de Medinaceli ${ }^{16}$. Además, el duque había escrito una carta al inquisidor D. Gonzalo de la Escalera diciendo que por medio del tal Jacobo "se tenían noticias de mucho provecho para el servicio de S.M." O sea, que servía de informador o espía, seguramente acerca de lo que ocurría en Berbería. En vista del carácter político del asunto, los inquisidores sevillanos prefirieron dejar que la Suprema resolviera $a^{17}$.

El importante núcleo hebraico de Liorna, en gran parte de origen peninsular, mantenía extensas relaciones comerciales, incluyendo Marruecos. La fragata Fátima, propiedad de la casa Buonacorsi, al retornar de un viaje a Salê se hubo de refugiar en Cádiz por falta de marinería; allí fueron presos Isaac di Gioseppe, su sobrino Abraham Caino y otro hebreo, que se remitieron a las cárceles de la Inquisición de Sevilla. El Gran Duque de Toscana escribió al Inquisidor General una carta fechada en Florencia, 19 de diciembre de 1670, interesándose por ellos, por ser

${ }^{13}$ Inquisición, 2.996.

${ }^{14} \mathrm{El}$ obispo o quien hace sus veces.

${ }^{15}$ Inquisición, 2.996.

${ }^{16}$ Los duques de Medinaceli habían reemplazado en la Capitanía General de las costas de Andalucía a ios de Medinasidonia desde que el duque D. Gaspar de Guzmán se hizo reo de conspiración en 1641.

${ }^{17}$ Inquisición, 3.001. 
súbditos suyos y pertenecientes a una Casa que venía prestándole servicios desde hacía noventa años.

El Inquisidor general pidió a la Inquisición de Sevilla infor. me, que evacuó el 7 de febrero de 1671 y en sustancia decía que en el mes de septiembre del año anterior se había recibido la noticia de que en una nao francesa habían llegado a Cádiz unos judíos y que el cónsul francés los encubría; se avisó al comisario en Cádiz que informara, y que si los judíos eran "de nación”, y pasaban a tierra a negociar, se les prendiera como si se tratara de bautizados. (Recordemos que la Inquisición sólo tenía jurisdicción sobre los bautizados). Si fuesen bautizados, o sea, judeoconversos, también deberían ser presos, incomunicados y confiscados sus bienes. La respuesta que llegó de Cádiz decía que aunque la nao venía a nombre de franceses, era propiedad de unos judíos de Salé, y que el duque de Veragua la había apresado y tenía en su poder a los judíos; había tomado el barco y lo que contenía en concepto de buena presa y a los judíos, al cabo de algún tiempo, los habia remitido a Liorna en un buque holandés (ibid.).

E1 16 de enero de 1676 Sevilla remitía a la Suprema unos autos sobre la venida a España de dos mozos "de nación y profesión hebreos", Levi Aboiser y Piutres Huisen, que decían querer bautizarse. Por lo pronto fueron puestos en la cárcel real de Cádiz, "executando lo que V.A. nos mandó para casos semejantes en carta del año 1663, y porque aviendo venido otro judío de nación llamado Jacobo Morreno fue V.A. servido mandar en carta de 24 de abril de 1668 que recibidas sus declaraciones lo remitiéramos al Ordinario en lo tocante al baptismo y tuviéramos cuidado particular de como procedía, representamos a V.A. el mal concepto que siempre hemos tenido de la venida de tales sugetos, y que la juzgamos efecto de los ardides y cautelas de la nazión hebrea, a la qual tan expresamente tienen cerrada la puerta las leyes del Reino".

El Tribunal de la Suprema ordenó se les pusiera separados en la cárcel de Sevilla y se les tomara declaración acerca, entre otros, de los siguientes puntos: dónde aprendieron el castellano; qué familias salieron de Hamburgo a Constantinopla a buscar al Mesías, "y pues dice que salió con el mismo intento y llegó a Liorno,.donde lo comunicó con algunos hebreos, de quienes fue informado que era falso, por lo que no prosiguió la jornada, dịga quiénes son y qué razones le dieron para mudar de parecer... Dirá también lo que oyó a los doctos de su ley después que de Lior no volvió a Amburgo, pues dice que le ocasionó dudas en ella... Pues dice que oyendo hablar al capitán Domingo de los Reyes de 
la ley de Dios conoció los engaños que padecía, declare qué habló dicho capitán... Pues dice que algunos judíos doctos de Amburgo y otras partes se pasan a Francia y otros lugares a ser cristianos, declare quienes son y las ciudades adonde fueron... Diga porqué en las declaraciones dice uno que fueron apresados por un navío inglés en la Canal de Inglaterra y el otro que estaban allí detenidos por temporal... con qué embarcación vinieron a España, el nombre del capitán y la nación, y qué conveniencias llevaban en la jornada de las Barbadas, porqué las dexaron, que esperaban en España, pues el fin sólo del Bautismo no los traxo, pues haviéndolos ofrecido Domingo de los Reyes traerlos y ayudarlos no lo aceptaron..."

Sevilla remitió los autos (que no figuran en el expediente) el 28 de marzo. El tribunal cree llégaron por arribada forzosa y luego montaron el cuento de la conversión. Temía que por tales medios "se abriera puerta a tales gentes, tomando pretexto tan sagrado como la conversión, para que los judaizantes encaminen a los hijos que han nacido en las synagogas o ciudades del Norte a estos Reinos y tengan en ellos personas de tanta confidencia para sus comercios y sean testigos y espías... todo lo cual cabe en el engañoso trato destas gentes, y parece confirmado el haver arribado a Cádiz otro tercer judío que se llama Mizuron, que queda en lâs cárceles deste Tribunal".

Respuesta de la Suprema: "Que se vuelvan estos procesos a los inquisidores de Sevilla para que poniendo en ellos las señas personales destos hebreos sean sueltos de la prisión y acudan al Ordinario a pedir el baptismo y se encargue a los ministros de los lugares donde fuesen a vivir tengan cuidado con su modo de vida y den quenta dello"'18.

En 1690 hallamos la noticia de estar presos y encausados dos judíos por haber entrado sin permiso; se llamaban Abraham Díaz de Fonseca y Sabato Pipero. Por entonces también José Bergamin y su criado Isaías, "judíos de nación y profesión", estaban presos en El Puerto de Santá María ${ }^{19}$.

Cerramos estas noticias con otras dos del año 1697: Sevilla remitía autos referentes a Abraham de Francia, judío de nación, bautizado con el nombre de Francisco María. Pedía licencia para ir a Amsterdam a traer a España a sus tres hijos. También pedía el bautismo un José Zulema, judío de Verona, de 23 años, que quería ser bautizado por el obispo, pero este rehusó, porque

${ }^{18}$ Ibid., 3.004.

${ }^{19}$ Ibid., 3,019. 
el mismo año otro judío había pedido ser bautizado por el vicario de El Puerto, por delegación del arzobispo de Sevilla, y al enterarse de que no le iba a dar un vestido nuevo para la ceremonia no quiso recibir el bautismo.

El tal Zulema se hospedaba en el convento Casa Grande de San Francisco de la capital hispalense, donde hoy se alzan los edificios de la Plaza Nueva. Los frailes lo apreciaban y trataban con gran regalo "por los buenos oficios que hace a los maestros de Teología, especialmente en la inteligencia de la lengua hebrea, la qual está enseñando a un sobrino del provisor de esta ciudad; al presente se halla enfermo y el provincial de San Francisco está prevenido para que solicite se le confiera el bautismo".

Estos son los hechos. ¿Qué conclusiones podríamos sacar? Dentro de lo aventurado que es deducir a partir de una muestra pequeña parece, en primer lugar, que la presencia de judíos "de nación y profesión", no judeoconversos, no bautizados, era un acontecimiento esporádico que se producía muy de tarde en tarde por motivaciones diversas: arribada forzosa, afanes comerciales y, tal vez en algunos casos, deseo de recibir el bautismo; pero sobre este punto las reservas de los inquisidores parecen fundadas.

Otra cosa que parece deducirse es que no arriesgaban demasiado; la venta como esclavos de los judíos que aportaron a Gibraltar (y sin duda tambiến de los moros que los acompañaban, aunque no se mencionan) se fundaría en la sospecha de ser un barco de piratas. En principio, todo navio berberisco se consideraba buena presa, y su tripulación tambiên. Por parte de la Inquisición no podían incurrir en pena puesto que no tenía jurisdicción sobre ellos; sólo les podía inculpar de haber entrado en España sin licencia. Con arreglo a la ley no derogada, pero en desuso, de los Reyes Católicos, incurrían en pena capital por la jurisdicción civil, no la eclesiástica. En la práctica parece que sólo se les aplicaba la deportación. 